Research Article

\title{
On the Inverse Problem for Some Topological Indices
}

\author{
Durbar Maji $\mathbb{D}$, ${ }^{1}$ Ganesh Ghorai $\left(\mathbb{D},{ }^{1}\right.$ Muhammad Khalid Mahmood $\mathbb{D}^{2}$ \\ and Md. Ashraful Alam ${ }^{3}{ }^{3}$ \\ ${ }^{1}$ Department of Applied Mathematics with Oceanology and Computer Programming, Vidyasagar University, \\ Midnapore 721102, India \\ ${ }^{2}$ Department of Mathematics, University of the Punjab, Lahore 54590, Pakistan \\ ${ }^{3}$ Department of Mathematics, Jahangirnagar University, Savar, Dhaka, Bangladesh
}

Correspondence should be addressed to Md. Ashraful Alam; ashraf_math20@juniv.edu

Received 11 September 2021; Revised 20 October 2021; Accepted 22 October 2021; Published 30 November 2021

Academic Editor: Lazim Abdullah

Copyright (C) 2021 Durbar Maji et al. This is an open access article distributed under the Creative Commons Attribution License, which permits unrestricted use, distribution, and reproduction in any medium, provided the original work is properly cited.

\begin{abstract}
The study of the inverse problem (IP) based on the topological indices (TIs) deals with the numerical relations to TIs. Mathematically, the IP can be expressed as follows: given a graph parameter/TI that assigns a non-negative integer value $(g)$ to every graph within a given family $(\mathscr{G})$ of graphs, find some $G \in \mathscr{G}$ for which $\operatorname{TI}(G)=g$. It was initiated by the Zefirov group in Moscow and later Gutman et al. proposed it. In this paper, we have established the IP only for the $Y$-index, Gourava indices, second hyper-Zagreb index, reformulated first Zagreb index, and reformulated $F$-index since they are closely related to each other. We have also studied the same which is true for the molecular, tree, unicyclic, and bicyclic graphs.
\end{abstract}

\section{Introduction}

Throughout the paper, we consider $€=(\mathrm{V}(\mathrm{E}), \mathrm{E}(\mathrm{E}))$ as a simple (without loops and multiple edge loops) finite graph that contains $|V(\mathrm{E})|=\mathrm{n}$ vertices and $|E(€)|=\mathrm{m}$ edges, respectively. The notation $\mathrm{d}(u / \mathrm{L})$ denotes the degree of a vertex $u \in V(Ł)$. All other notations and terminologies used but not clearly stated in this paper may be followed from [1].

In chemical graph theory, a TI, usually known as a molecular descriptor, can be expressed by a real number calculated from a chemical/molecular graph which is the representation of a chemical compound by replacing atoms with vertices and bonds with edges. The TI is calculated for evaluating the information about the atomic constitution and bond characteristics of a molecule/chemical compound. The TI of a molecular graph is a numerical number that enables us to collect information about the concerned chemical structure. It helps us to know its hidden properties without performing experiments [2-4]. The TIs also correlate and predict several physical, chemical, biological, pharmaceutical, pharmacological activities/properties from molecular structures of graphs corresponding to real-life situations. The IP is defined as the feasibility of finding/modeling the chemical structure represented by a graph whose index value is equal to a given nonnegative integer for the integer-valued problem. In the QSAR and QSPR studies [5], a method by which it is possible to predict the properties of a given molecular structure is called a forward problem. The inverse problem is concerned that, one can design the exact molecular structure that satisfies the given target properties by applying the forward problem solution.

The most popular as well as the oldest degree-based graph indices are the first and second Zagreb indices. Gutman et al. introduced the first Zagreb index $M_{1}(€)$ in [6] and second Zagreb index $M_{2}(€)$ in [7]. They are defined, respectively, as

$$
\begin{aligned}
& M_{1}(\mathrm{E})=\sum_{u \in V(\mathrm{E})} \mathrm{d}^{2}\left(\frac{u}{\mathrm{E}}\right)=\sum_{u v \in E(\mathrm{E})}\left[\mathrm{d}\left(\frac{u}{\mathrm{E}}\right)+\mathrm{d}\left(\frac{v}{\mathrm{E}}\right)\right], \\
& M_{2}(\mathrm{E})=\sum_{u v \in E(\mathrm{E})} \mathrm{d}\left(\frac{u}{\mathrm{E}}\right) \mathrm{d}\left(\frac{v}{\mathrm{E}}\right) .
\end{aligned}
$$

In 2016, Farahani et al. [8] defined the second hyperZagreb index as follows: 


$$
H M_{2}(£)=\sum_{u v \in(E)}\left[d\left(\frac{\mathrm{u}}{\mathrm{E}}\right) \mathrm{d}\left(\frac{\mathrm{v}}{\mathrm{E}}\right)\right]^{2} .
$$

Kulli [9] introduced the first and second Gourava indices, defined, respectively, as

$$
\begin{aligned}
& \mathrm{GO}_{1}(\mathrm{E})=\sum_{u v \in E(\mathrm{E})}\left[\mathrm{d}\left(\frac{u}{\mathrm{E}}\right)+\mathrm{d}\left(\frac{v}{\mathrm{E}}\right)+\mathrm{d}\left(\frac{u}{\mathrm{E}}\right) \mathrm{d}\left(\frac{v}{\mathrm{E}}\right)\right], \\
& \mathrm{GO}_{2}(\mathrm{E})=\sum_{u v \in E(\mathrm{E})}\left[\left(\mathrm{d}\left(\frac{u}{\mathrm{E}}\right)+\mathrm{d}\left(\frac{v}{\mathrm{E}}\right)\right) \mathrm{d}\left(\frac{u}{\mathrm{E}}\right) \mathrm{d}\left(\frac{v}{\mathrm{E}}\right)\right] .
\end{aligned}
$$

Milicevic proposed the reformulated first Zagreb index $E M_{1}(£)$ in [10], defined as

$$
E M_{1}(\mathrm{E})=\sum_{\mathrm{e} \in \mathrm{E}(\mathrm{E})} \mathrm{d}^{2}\left(\frac{\mathrm{e}}{\mathrm{E}}\right) ; \mathrm{d}\left(\frac{\mathrm{e}}{\mathrm{E}}\right)=\mathrm{d}\left(\frac{\mathrm{u}}{\mathrm{E}}\right)+\mathrm{d}\left(\frac{\mathrm{v}}{\mathrm{E}}\right)-2 .
$$

Liu et al. [11] put forward the reformulated $F$-index, and it is defined as follows:

$$
R F(E)=\sum_{e \in E(E)} d^{3}\left(\frac{e}{E}\right)=\sum_{e \sim f \in E(E)}\left[d^{2}\left(\frac{e}{E}\right)+d^{2}\left(\frac{f}{E}\right)\right] .
$$

Alameri et al. [12] introduced $Y$-index, and it is defined by

$$
Y(\mathrm{E})=\sum_{\mathrm{u} \in \mathrm{V}(\mathrm{G})} \mathrm{d}^{4}\left(\frac{\mathrm{u}}{\mathrm{E}}\right)=\sum_{\mathrm{uv} \in \mathrm{E}(\mathrm{E})}\left[\mathrm{d}^{3}\left(\frac{\mathrm{u}}{\mathrm{E}}\right)+\mathrm{d}^{3}\left(\frac{\mathrm{v}}{\mathrm{E}}\right)\right] .
$$

Graph theory, a branch of mathematics, provides the tools for solving problems of information theory, computer sciences, physics, and chemistry [13-15]. The study of the IP is encountered in various fields of science, especially in mathematics and chemistry. The IP for a TI is defined as follows: for a given TI and a non-negative integer value $(x)$, find (chemical) graph (Ł) for which $\mathrm{TI}(€)=\mathrm{x}$. Also, the inverse existence problem [16] for the pair $(G, \Gamma)$ can be asked as follows: given $(\mathscr{G})$ a class of graph and function $\Gamma: \mathscr{G} \longrightarrow H$, for which $g \in H$ there is $G \in \mathscr{G}$ with $\Gamma(G)=g$ ? The idea of the IP based on TIs was initiated by the Zefirov group in Moscow [5, 17, 18] and was first proposed by Gutman et al. in [19]. The IP for Wiener index was solved in [20]. In [21], the IP was studied for sigma index as well as for acyclic, unicyclic, and bicyclic graphs. The same problem for the Steiner Wiener index was also solved in [22]. This type of problem for the Zagreb indices, forgotten Zagreb index, and the hyper-Zagreb index was studied in [23]. Tavakoli et al. [24] addressed the IP for first Zagreb index. Also, the IP for some graph indices was investigated in [25]. In [26], Czabarka et al. solved the IP for certain tree parameters. To study more about the inverse problems and the topological indices of graph operations, one can see these references [27-32].

There are so many benefits in the solution of IP. It helps to design of combinatorial libraries for drug discovery in combinatorial chemistry [33]. It may be helpful in speeding up the discovery of lead compounds with desired properties [34]. Also, the IP plays its significance in the application of trees [35] such as the field of algorithms, chemical graph theory, signal processing, and electrical circuits.

\section{Preliminaries}

To study the IP for $Y$-index, we will use the following crucial observation.

Let $€$ be a graph having $u$ and $v$ as vertices which are adjacent to each other. We subdivide each edge $(u v)$ by introducing a new vertex $(w)$ (of degree 2) to construct a new graph $\mathrm{E}^{*}$ (see Figure 1 ).

Here, the $Y$-index of the new graph $\varkappa^{*}$ will be sixteen which is more than the graph $€$.

Lemma 1. By applying the transformation $E \longrightarrow E^{*}$, the $Y$-index value will be increased by 16. That is, $Y\left(t^{*}\right)=Y(Ł)+16$.

Proof. Let us consider the graph $€$ with vertices $u$ and $v$ of degrees $x$ and $y$, respectively. Since in the new constructed graph $\iota^{*}$, a new vertex $w$ is inserted between $u$ and $v$,

$$
\begin{aligned}
& Y\left(\mathrm{E}^{*}\right)-Y(\mathrm{E})=\mathrm{d}^{4}\left(\frac{u}{\mathrm{E}^{*}}\right)+\mathrm{d}^{4}\left(\frac{w}{\mathrm{E}^{*}}\right)+\mathrm{d}^{4}\left(\frac{v}{\mathrm{E}^{*}}\right) \\
& -\mathrm{d}^{4}\left(\frac{u}{E}\right)-\mathrm{d}^{4}\left(\frac{v}{\mathrm{E}}\right) \\
& =x^{4}+16+y^{4}-x^{4}-y^{4} \\
& =16 \text {. }
\end{aligned}
$$

Lemma 2. If either $d(u / t)=2$ or $d(v / €)=2$ (or both), then by the means of the above transformation $€ \longrightarrow E^{*}$, the value of the first Gourava index increases by 8. That is,

$$
\mathrm{GO}_{1}\left(\mathrm{E}^{*}\right)=\mathrm{GO}_{1}(\mathrm{E})+8
$$

Similarly, the value of the second Gourava index increases by 16. Thus,

$$
\mathrm{GO}_{2}\left(\mathrm{E}^{*}\right)=\mathrm{GO}_{2}(\mathrm{E})+16
$$

Lemma 3. If either $d(u / t)=2$ or $d(v / €)=2$ (or both), then by means of the above transformation $E \longrightarrow E^{*}$, the value of the second hyper-Zagreb index increases by 16. That is,

$$
H M_{2}\left(£^{*}\right)=H M_{2}(£)+16
$$

Lemma 4. If either $d(u / €)=2$ or $d(v / €)=2$ (or both), then by applying the transformation $E \longrightarrow E^{*}$, the values of the reformulated first Zagreb index and reformulated F-index of the graph $\mathrm{E}$ increase by 4 and 8 , respectively. Thus,

$$
\begin{aligned}
E M_{1}\left(\longleftarrow^{*}\right) & =E M_{1}(Ł)+4, \\
\mathrm{RF}\left(\mathrm{Ł}^{*}\right) & =\mathrm{RF}(\mathrm{E})+8 .
\end{aligned}
$$




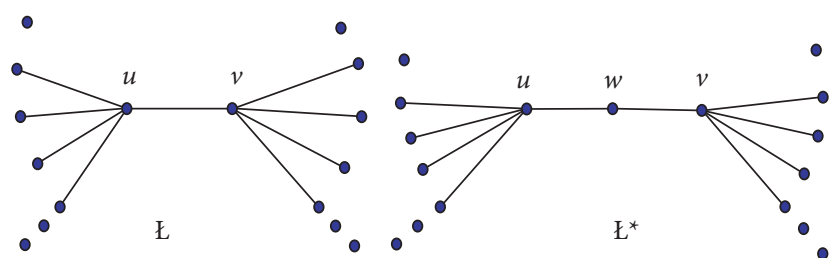

FIgURE 1: The graphs (a) $€$ and (b) $£^{*}$ used in auxiliary Lemmas 1-4.

\section{Main Results and Discussion}

In graph theory, the IP based on the TIs is an interesting one among the problems associated with the estimation of different graph invariants/TIs such as chromatic number, connectivity, girth, and number of independent sets. The IP plays a crucial role in many areas of science, especially in mathematics. In this section, we have investigated the IP for $Y$-index, Gourava indices, second hyper-Zagreb index, reformulated first Zagreb index, and reformulated $F$-index. Additionally, we have developed the same problem for molecular, tree, acyclic, unicyclic, and bicyclic graphs.

3.1. The IP for $Y$-Index. Here we will discuss the IP for $Y$-index.

Theorem 1. The Y-index for connected graphs can take all positive even integers, for $4,6,8,10,12,14,16,2(8 i+2), 2(8 j+3), 2(8 k+4), 2(8 m+$ $5), 2(8 n+6), 2(8 p+7) \quad$ where $i=1,2, \ldots, 4 ; j=1,2, \ldots$, $9 ; k=1,2, \ldots, 14 ; m=1,2, \ldots, 19 ; n=1,2, \ldots, 24 ; \quad$ and $p=1,2, \ldots, 29$.

Proof. Proof. To prove the theorem, we establish a set of graphs $Y_{0}, Y_{2}, Y_{4}, Y_{6}, Y_{8}, Y_{10}, Y_{12}, Y_{14}$ whose $Y$-index values are $48,2,84,166,248,330,412$, and 494 , respectively. These numbers are congruent to $0,2,4,6,8,10,12$, and $14(\bmod$ 16), respectively.

Consider the cyclic graphs $C_{n}$ for $n \geq 3$. Clearly, in Figure 2(a), $Y\left(Y_{0}=C_{3}\right)=48, Y\left(C_{4}\right)=64, Y\left(C_{5}\right)=80$, and $Y\left(C_{n}\right)=16 n$ for $n \geq 3$. Now we apply Lemma 1 for each graph in Figure 2. Thus, $Y\left(Y_{0}\right)$ takes all those even positive integer values which are divisible by 16 , except 16 and 32 .

In Figure 2(b), $Y\left(P_{2}\right)=2$. By applying the transformation in Lemma 1, we arrive at graphs whose $Y$-index values are $18,34,50,66$, and so on. There are the path graphs. Thus, $Y(€)$ takes all positive even integer values which are congruent to $2(\bmod 16)$.

Now consider the graph in Figure 2(c) with $Y\left(Y_{4}\right)=84$. By applying Lemma 1 , we can obtain graphs with $Y$-index values $100,116,132,148, \ldots$ Here, $Y\left(Y_{4}\right)$ contains all positive even integer values $\equiv 4(\bmod 16)$, except the integers $20,36,52$, and 68 .

The graph is depicted in Figure 2(d) with $Y\left(Y_{6}\right)=166$, and then by using Lemma 1 , we can take the graphs with $Y$-index values $182,198,214,230, \ldots$, and so on. Therefore, $Y\left(Y_{6}\right)$ covers all positive even integer values $\equiv 6(\bmod 16)$ and $\geq 166$. Obviously, the integers $6,22, \ldots, 134,150$ are not covered by the construction.
In Figure 2(e), we have $Y\left(Y_{8}\right)=248$, and then by using Lemma 1, we can take the graphs with $Y$-index values $264,280,296,314, \ldots$, and so on. So, $Y\left(Y_{8}\right)$ takes all positive even integer values $\equiv 8(\bmod 16)$ and $\geq 248$. Obviously, the integers $24,40, \ldots, 216,232$ are not covered by the construction.

The graph in Figure 2(f) contains $Y\left(Y_{10}\right)=330$. Again by Lemma 1, $Y\left(Y_{10}\right)$ goes to all those positive even integer values $\equiv 10(\bmod 16)$ and $\geq 330$ giving $330,348,364,380$, ..., and so on.

From Figure $2(\mathrm{~g})$, we have $Y\left(Y_{12}\right)=412$. By applying Lemma $1, Y\left(Y_{12}\right)$ takes all positive even integer values $\equiv 12$ ( $\bmod 16)$ and also $\geq 412$ having $412,428,444,460, \ldots$, and so on.

The graph in Figure $2(\mathrm{~h})$ has $Y\left(Y_{14}\right)=494$. By applying Lemma $1, Y\left(Y_{14}\right)$ takes all positive even integer values $\equiv 14$ $(\bmod 16)$ and also $\geq 494$ taking $494,510,526,542, \ldots$, and so on. There exist no connected graphs with the $Y$-indices mentioned in Table 1.

Corollary 1. The Y-index of a tree (or molecular) graph can take all positive even integers, except for $4,6,8,10,12,14,16,2(8 r+2), 2(8 s+3), 2(8 t+4), 2(8 w+$ $5), 2(8 x+6), 2(8 y+7) \quad$ where $\quad r=1,2,3,4 ; s=1,2$, $\ldots, 9 ; t=1,2, \ldots, 14 ; w=1,2, \ldots, 19 ; x=1,2, \ldots, 24$; and $y=1,2, \ldots, 29$.

Corollary 2. Let $€$ be a connected unicyclic or bicyclic graph. Then, there exists the $Y$-index of the form $16 h+2 k$ for all nonnegative integers where $h \neq 0$ and $1 \leq k \leq 7$.

Proof. Proof. Let $\mathrm{E}_{1}$ be a unicyclic graph which is obtained by adding a path of length two to any vertex $u$ of the cyclic graph $C_{n}$ for $n=5$. Thus, $Y\left(£_{1}\right)=162=16 \times 10+2 \times 1$. Similarly, the unicyclic graph $E_{2}$ is obtained by adding another path of length two to one of the two adjacent vertices to $u$ that lie on $£_{1}$ (see Figure 3 ). We get $Y\left(t_{2}\right)=244$.

The bicyclic graph $\mathrm{E}_{3}$ is obtained by gluing two cyclic graphs with one side of both, and we have $Y\left(t_{3}\right)=306$ which also can be expressed in the said form. Similarly, another bicyclic graph $£_{4}$ is obtained by adding a path with length two to any vertex $u$ of $\biguplus_{3}$. Thus, $Y\left(E_{4}\right)=388$ is of the form $16 h+2 k$ for $h=24, k=2$.

3.2. The IP for Gourava Indices. Here we study the IP for Gourava indices.

Theorem 2. The first Gourava index of a connected graph can take any positive integer except for $1,2,4,5,6,7,8,9,11$, $12,13,14,15,16,17,19,20,22,23,25,27,28,29,31,33,35$, $41,44,49,57$, and 73 .

Proof. By applying Lemma 2, we construct eight series of graphs $\left(G_{j}, j=0,1,2, \ldots, 7\right)$ containing at least one vertex of degree 2 , whose $\mathrm{GO}_{1}$-values are of the form $8 s+$ $t$ for $t=0,1,2, \ldots, 7$. These graphs are drawn in Figures $4(\mathrm{a})-4(\mathrm{~h})$. 


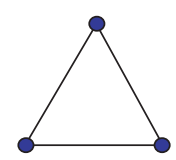

(a) $Y_{0}$

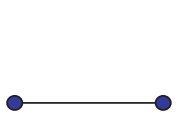

(b) $Y_{2}$

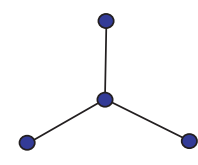

(c) $Y_{4}$

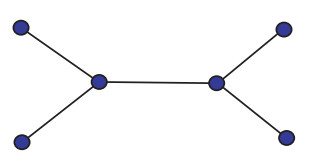

(d) $Y_{6}$

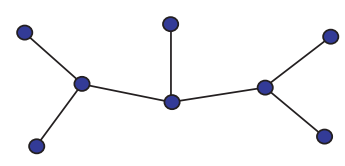

(e) $Y_{8}$

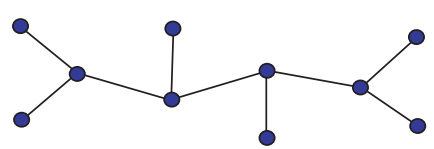

(f) $Y_{10}$

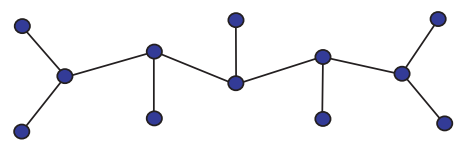

(g) $Y_{12}$

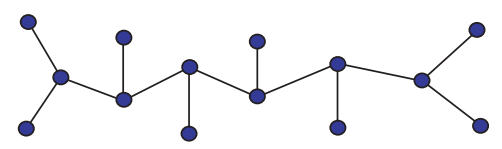

(h) $Y_{14}$

Figure 2: The graphs $Y_{i}$, for $i=0,2,4,6,8,10,12$, and 14 : (a) $Y_{0}$, (b) $Y_{2}$, (c) $Y_{4}$, (d) $Y_{6}$, (e) $Y_{6}$, (f) $Y_{8}$, (g) $Y_{10}$, (h) $Y_{12}$, and (i) $Y_{14}$.

TABLE 1: $Y$-index values which do not exist.

\begin{tabular}{ccccccc}
\hline$Y_{0}$ & $Y_{4}$ & $Y_{6}$ & $Y_{8}$ & $Y_{10}$ & $Y_{12}$ \\
\hline \multirow{16}{*}{} & 4 & 6 & 8,24 & 10,26 & $12,28,44$ & $14,30,46$ \\
32 & 20 & 22 & 40,56 & 42,58 & $60,76,92$ & $62,78,94$ \\
& 36 & 38 & 72,88 & 74,90 & $108,124,140$ & $110,126,142$ \\
& 52 & 54 & 104,120 & 106,122 & $156,172,188$ & $158,174,190$ \\
& 68 & 70 & 136,152 & 138,154 & $204,220,236$ & $206,222,238$ \\
& & 10 & 168,184 & 170,186 & $252,268,284$ & $302,318,334$ \\
& 118 & 200,216 & 202,218 & $300,316,332$ & $350,366,382$ \\
& & 232 & 234,250 & $348,364,380$ & 396 & $398,414,430$ \\
& 134 & & 266,282 & 298,314 & & $446,462,478$ \\
\hline
\end{tabular}

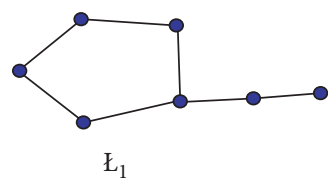

$£_{1}$ be a unicyclic graph with $\mathrm{Y}\left(\mathrm{E}_{1}\right)=162$

(a)

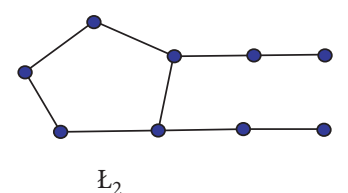

$\mathrm{E}_{2}$ be a unicyclic graph with $\mathrm{Y}\left(\mathrm{E}_{2}\right)=244$

(b)

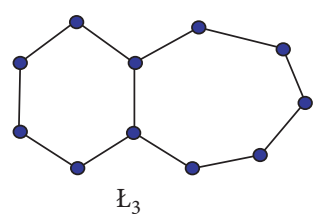

$\mathrm{E}_{3}$ be a bicyclic graph with $\mathrm{Y}\left(\mathrm{E}_{3}\right)=306$

(c)

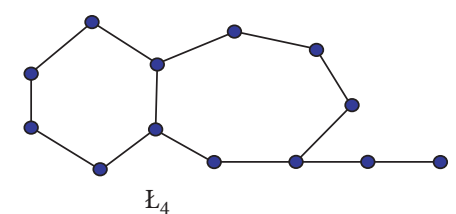

$€_{4}$ be a bicyclic graph with $\mathrm{Y}\left(\mathrm{E}_{4}\right)=388$

(d)

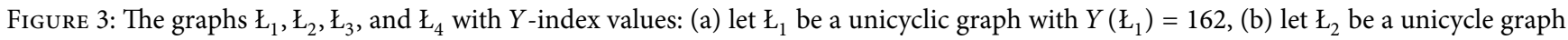
with $Y\left(€_{3}\right)=244$, (c) let $£_{3}$ be a bicyclic graph with $Y\left(E_{3}\right)=306$, and (d) let $£_{4}$ be a bicyclic graph with $Y\left(E_{4}\right)=388$.

Consider a cycle graph $C_{n}$ with $n \geq 3$. Clearly, $\mathrm{GO}_{1}\left(C_{n}\right)=8 n$. Therefore, $\mathrm{GO}_{1}(£)$ can take all those positive integer values which are divisible by 8 . From the graph $G_{0}$ (Figure 4) and Lemma 2, we obtain the graphs with $\mathrm{GO}_{1}(\mathrm{E})$-values $32,40,48,56,64, \ldots$. Thus, $\mathrm{GO}_{1}((\textrm{)})$ takes all positive integers $\equiv 0(\bmod 8)$ and $\geq 24$.

Consider the graph $G_{1}$ in Figure 4 with $\mathrm{GO}_{1}(£)=81$, i.e., $\mathrm{GO}_{1}(€)$ implies all positive integer values $\equiv 1(\bmod 8)$. Then, by Lemma 2, we obtain graphs with $\mathrm{GO}_{1}(£)=89,97$, $105,113,121, \ldots$. Again for the graph $G_{2}, \mathrm{GO}_{1}(£)=10$. Thus, we can arrive at graphs whose $\mathrm{GO}_{1}$ values are 18,26 , $34,42,50,58,66,74,82, \ldots$. Similarly, by applying Lemma 2 to the graphs $G_{3}, G_{4}, G_{5}, G_{6}$, and $G_{7}$, we get the graphs with $\mathrm{GO}_{1}=59,67,75,83,91,99,107,115, \ldots, 60,68,76,84,92$,
$100,108, \ldots, 45,53,61,69,77,85, \ldots, 38,46,54,62,70,78$, $\ldots$, and $47,55,63,71,79,87, \ldots$, respectively. The star graphs $S_{4}, S_{5}$ and examples depicted in Figures 2(d) and 5(b) show that there exist graphs with $\mathrm{GO}_{1}(£)$ as $21,36,43$, and 65 , respectively. There exist no connected graphs with first Gourava index as listed in Table 2.

Corollary 3. The first Gourava index of a tree (or molecular) graph can take any positive integer, except for 1, 2, 4, 5, 6, 7, 8, $9,11,12,13,14,15,16,17,19,20,22,23,25,27,28,29,31,33$, $35,41,44,49,57$, and 73 .

Now we study to settle the IP for the second Gourava index. 


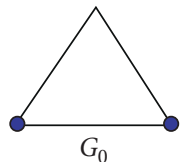

$G O_{1}\left(G_{0}\right)=24$

(a)

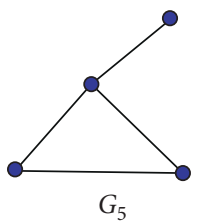

$G O_{1}\left(G_{5}\right)=37$

(f)

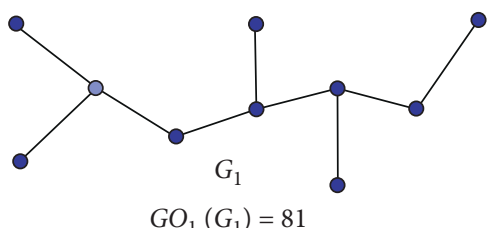

(b)

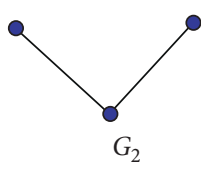

$G O_{1}\left(G_{2}\right)=10$

(c)

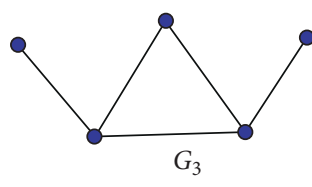

$G O_{1}\left(G_{3}\right)=51$

(d)

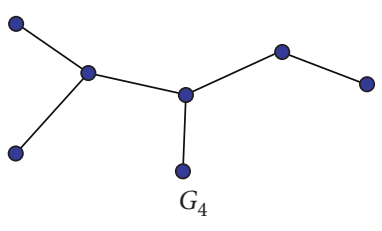

$G O_{1}\left(G_{4}\right)=52$

(e)

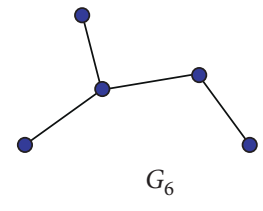

$G O_{1}\left(G_{6}\right)=30$

(g)

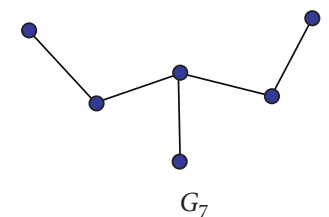

$G O_{1}\left(G_{7}\right)=39$

(h)

Figure 4: The graphs $G_{j}$, for $j=0,1,2, \ldots, 7$ with first Gourava index values: (a) $G_{0} \mathrm{GO}_{1}\left(G_{0}\right)=24$, (b) $G_{1} \mathrm{GO}_{1}\left(G_{1}\right)=81,(\mathrm{c}) G_{2}$ $\mathrm{GO}_{1}\left(G_{2}\right)=10$, (d) $G_{3} \mathrm{GO}_{1}\left(G_{3}\right)=51$, (e) $G_{4} \mathrm{GO}_{1}\left(G_{4}\right)=52$, (f) $G_{5} \mathrm{GO}_{1}\left(G_{5}\right)=37$, (g) $G_{6} \mathrm{GO}_{1}\left(G_{6}\right)=30$, and (h) $G_{7} \mathrm{GO}_{1}\left(G_{7}\right)=39$.

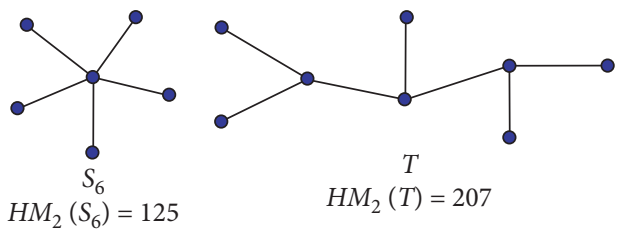

(a)

(b)

Figure 5: The star graph (a) $S_{6}$ and tree (b) $T$ with second hyper-Zagreb index values.

TABLe 2: The first Gourava index values which do not exist.

\begin{tabular}{lccccccc}
\hline$G_{0}$ & $G_{1}$ & $G_{2}$ & $G_{3}$ & $G_{4}$ & $G_{5}$ & $G_{6}$ \\
\hline 8 & 1 & 2 & & 4 & 5 & 6 \\
16 & 9 & & 11 & 12 & 13 & 14 \\
& 17,25 & & 19 & 20 & 29 & 22 \\
& 33,41 & 27 & 28 & & \\
& 49,57 & 35 & 44 & & \\
& 73 & & & & \\
\hline
\end{tabular}

Theorem 3. The second Gourava index of a connected graph can take any positive even integer except for $4,6,8,10,14,16$, $20,22,24,26,30,32,34,38,40,42,46,50,52,54,56,58,62$, $66,68,70,72,74,78,82,86,90,94,98,102,106,110,118$, 122 , and 134 .

Proof. Consider first path graphs $P_{n}$ for $n \geq 2$. It is clear that $\mathrm{GO}_{2}\left(P_{2}\right)=2$ and $\mathrm{GO}_{2}\left(P_{3}\right)=12$. By Lemma 2, since $\mathrm{GO}_{2}\left(P_{n}\right)=16 n-36$ for $n \geq 3$, we obtain the graphs whose $\mathrm{GO}_{2}$-values are $28,44,60,76,92,108, \ldots$ which are congruent to $12(\bmod 16)$. If we consider a cyclic graph $C_{n}$ with $n$ vertices, then $\mathrm{GO}_{2}\left(C_{n}\right)=16 n$ for $(n \geq 3)$. Clearly, we get the graphs with $\mathrm{GO}_{2}$-values $48,64,80,96,112, \ldots$ Now the graph $G_{7}$ drawn in Figure 4 has $\mathrm{GO}_{2}(\mathrm{E})=84$. Therefore, by applying Lemma 2, we obtain the graphs with second Gourava index values $100,116,132,148,164, \ldots$ The graphs $G_{4}$ and $G_{5}$ in Figure 4 contain $\mathrm{GO}_{2}(\mathrm{E})=126$ and $\mathrm{GO}_{2}(\mathrm{E})=88$, respectively. Therefore, by Lemma $2, \mathrm{GO}_{2}(£)$ obtains all those even integer values $126,142,158,174,190,206,222, \ldots$ and $104,120,136,152, \ldots$, respectively. In same procedure, from Figure 4 , we get the graph $G_{3}$ with $\mathrm{GO}_{2}(£)=138$. So, it follows the $\mathrm{GO}_{2}$-values $154,170,186,202,218, \ldots$.

In Figure 6, by Lemma 2, we have $G_{2}\left(G_{8}\right)=150$ and $\mathrm{GO}_{2}\left(G_{9}\right)=114$ with. Then by using the Lemma 2 , we can take the graphs with $166,182,198,214, \ldots$ and $130,146,162$, $178,194, \ldots$, respectively. The integers not covered by the above transformation for the second Gourava index are listed in Table 3.

Corollary 4. The second Gourava index of a tree (or molecular) graph can take any positive even integer, except for 4 , $6,8,10,14,16,20,22,24,26,30,32,34,38,40,42,46,50,52$, $54,56,58,62,66,68,70,72,74,78,82,86,90,94,98,102$, $106,110,118,122$, and 134 . 


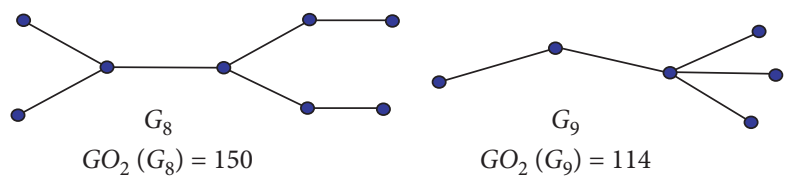

Figure 6: The graphs (a) $G_{8}$ and (b) $G_{9}$ with second Gourava index values.

TABle 3: The second Gourava index values which do not exist.

\begin{tabular}{ccccccc}
\hline$G_{0}$ & $G_{2}$ & $G_{4}$ & $G_{6}$ & $G_{8}$ & $G_{10}$ & $G_{14}$ \\
\hline \multirow{3}{*}{16} & & 4 & 6 & 8 & 10 & 14 \\
32 & 34 & 20 & 22 & 24 & 26 & 30 \\
& 50 & 52 & 54 & 56 & 58 & 62 \\
& 66 & 68 & 70 & 72 & 74 & 78 \\
& 82 & & 86 & & 90 & 94 \\
& 98 & & 102 & & 106 & 110 \\
& & & 118 & & 122 & \\
& & & 134 & & & \\
\hline
\end{tabular}

\subsection{The IP for Second Hyper-Zagreb Index}

Theorem 4. The second hyper-Zagreb index of a connected graph can be any positive integer, except 2, 3, 4, 5, 6, 7, 9, 10, $11,12,13,14,15,16,17,18,19,20,21,22,23,25,26,28,29$, $30,31,32,33,34,35,36,37,38,39,41,42,43,44,45,46,47$, $49,50,51,52,53,54,55,57,59,60,61,62,63,65,66,67,68$, $69,70,71,73,75,76,77,78,79,81,82,83,84,85,86,87,91$, $92,93,94,95,98,99,100,101,102,103,107,109,110,111$, $114,115,118,119,123,126,127,130,131,133,134,135,141$, $142,143,146,147,149,150,151,157,158,159,163,165,167$, $173,174,175,181,183,190,191,199,206,215,222,223,231$, 239, 255, and 271 .

Proof. We construct a series of sixteen graphs such as $H_{0}, H_{1}, H_{2}, \ldots, H_{15}$. The $H_{2}$ values of these graphs can be expressed in the form $16 h+i$ for $i=0,1,2, \ldots, 15$. In Figure 7 , we construct the graphs $H_{k}$ for $k=2,3,4,5,6,7$ and $11,12,13,14,15$. Note that the graphs $H_{0}, H_{1}, H_{8}, H_{9}, H_{10}$ are similar to Figures $4(\mathrm{a}), 4(\mathrm{f}), 4(\mathrm{c}), 4(\mathrm{~h})$, and $4(\mathrm{~g})$ respectively. We have $\mathrm{HM}_{2}\left(H_{0}\right)=48$. Then by using Lemma 3, we can take the graphs with $\mathrm{HM}_{2}$ values 64, 80, $96,112, \ldots$ which are congruent to $0(\bmod 16)$. Secondly, consider the graph $\mathrm{H}_{1}$ which generates the $\mathrm{HM}_{2}$-values $97,113,129,145,161, \ldots$, and all these are congruent to 1 $(\bmod 16)$.

Since $\mathrm{HM}_{2}\left(\mathrm{H}_{2}\right)=162$, by mean of the construction method upon the graph $\mathrm{H}_{2}$ from the Lemma 3, we get the graphs with $\mathrm{HM}_{2}$ values $178,194,210,226, \ldots$ which are congruent to $2(\bmod 16)$. For $\mathrm{H}_{3}$, the $\mathrm{HM}_{2}$-values cover the integers $179,195,211,227, \ldots$ which are $\equiv 3(\bmod 16)$. Analogously, the $\mathrm{HM}_{2}$ values for the graph $\mathrm{H}_{4}$ cover all the integers $116,132,148, \ldots$, and all these numbers are congruent to $4(\bmod 16)$. For $H_{5}$, it provides the $\mathrm{HM}_{2}$ values $197,213,229, \ldots$ which are $\equiv 5(\bmod 16)$. For $H_{6}$ there exist $H M_{2}$ values $166,182,198, \ldots$ which are $\equiv 6(\bmod 16)$. It follows $247,263,379, \ldots$ for the graph $H_{7}$, and these integers are congruent to 7 ( mod 16$)$. Similarly by Lemma 3 , we get for the graphs $H_{8}, H_{9}, H_{10}, H_{11}, H_{12}, H_{13}, H_{14}, H_{15}$ with Now, using the construction method in Lemma 3 to $H_{8}, H_{9}, H_{10}, H_{11}, H_{12}, H_{13}, H_{14}$, and $H_{15}$, we can generate the graphs with $\mathrm{HM}_{2}$ values $8,24,40, \ldots$ congruent to 8 $(\bmod 16) ; 89,105,121, \ldots$ congruent to $9(\bmod 16) ; 58,74$, $90, \ldots$ congruent to $10(\bmod 16) ; 139,155,171, \ldots$ congruent to $11(\bmod 16) ; 108,124,140, \ldots$ congruent to 12 $(\bmod 16) ; 189,205,221, \ldots$ congruent to $13(\bmod 16) ; 238$, $254,270, \ldots$ congruent to $14(\bmod 16)$; and $257,303,319, \ldots$ congruent to $15(\bmod 16)$, respectively.

The examples drawn in the Figures 2(c), 2(d), 5(a), and 5(b) have $\mathrm{HM}_{2}$ values $117,27,125$, and 207, respectively. These numbers are congruent to $5,11,13$, and $15(\bmod 16)$, chronologically. There exist no connected graphs with the $\mathrm{HM}_{2}$-indices mentioned in Table 4.

Corollary 5. The second hyper-Zagreb index of a tree (or molecular) graph can be any positive integer, except 2, 3, 4, 5, $6,7,9,10,11,12,13,14,15,16,17,18,19,20,21,22,23,25$, $26,28,29,30,31,32,33,34,35,36,37,38,39,41,42,43,44$, $45,46,47,49,50,51,52,53,54,55,57,59,60,61,62,63,65$, $66,67,68,69,70,71,73,75,76,77,78,79,81,82,83,84,85$, $86,87,91,92,93,94,95,98,99,100,101,102,103,107,109$, $110,111,114,115,118,119,123,126,127,130,131,133,134$, $135,141,142,143,146,147,149,150,151,157,158,159,163$, $165,167,173,174,175,181,183,190,191,199,206,215,222$, 223, 231, 239, 255, and 271.

\subsection{The IP for Reformulated First Zagreb Index}

Theorem 5. The first reformulated Zagreb index of a connected graph can take all positive even integer values except for 4 and 8.

Proof. At first, we consider the path $P_{n}$ with $n \geq 3$. The Rez-value for $P_{3}$ is equal to 2. By Lemma 4, we obtain graphs with Rez-values $6,10,14,18, \ldots$, and so on. Also, since $\operatorname{Rez}\left(S_{3}\right)=12$, by means of the construction described in Lemma 4, we have the graphs whose Rez-values are 16, 20, $24,28,32,36,40, \ldots$. Hence, Rez $(€)$ covers all positive even integers except 4 and 8.

Corollary 6. The first reformulated Zagreb index of a tree (or molecular) graph can take all positive even integer values, except for 4 and 8.

\subsection{The IP for Reformulated F-Index}

Theorem 6. The reformulated F-index of a connected graph can be any positive even integer, except for 4, 6, 8, 12, 14, 16, $20,22,28,30,36,38,46,54$, and 62 .

Proof. For the path graphs $P_{3}$, we get $\operatorname{RF}\left(P_{3}\right)=2$. Thus, by applying Lemma 4 , we obtain graphs with $\mathrm{RF}(\mathrm{E})$-values equal to $10,18,26,34, \ldots$. Similarly, for the cyclic graph $C_{3}$, we have $\operatorname{RF}\left(C_{3}\right)=24$ and next obtained graphs having $\mathrm{RF}(\mathrm{\ell})$-values $32,40,48,56, \ldots$. In an analogous manner, 

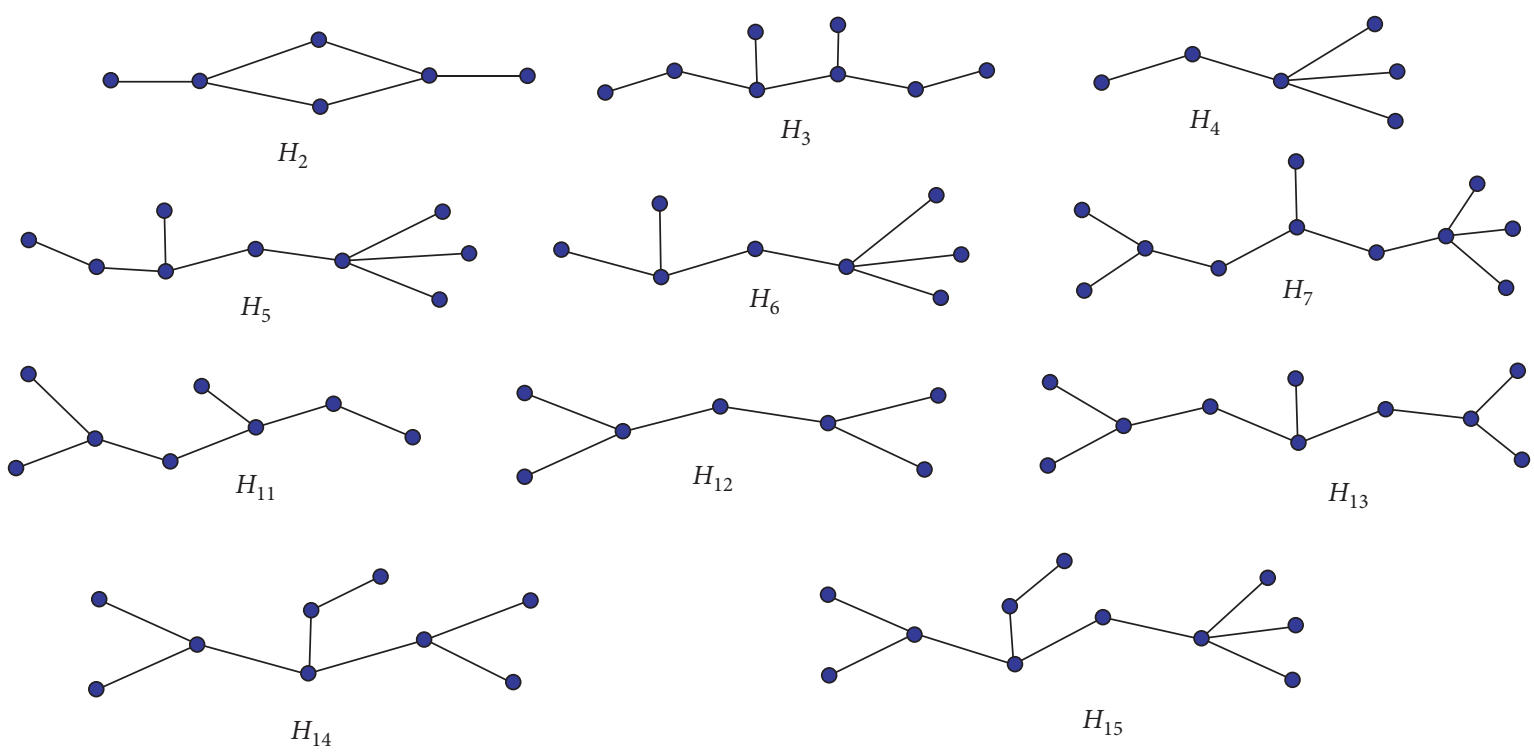

Figure 7: The graphs $H_{k}$, for $k=2,3,4,5,6,7$ and 11, 12, 13, 14, 15.

TABLE 4: $H M_{2}$ values which do not exist.

\begin{tabular}{|c|c|c|c|c|c|c|c|c|c|c|c|c|c|c|}
\hline$H_{0}$ & $H_{1}$ & $\mathrm{H}_{2}$ & $\mathrm{H}_{3}$ & $H_{4}$ & $H_{5}$ & $H_{6}$ & $\mathrm{H}_{7}$ & $H_{9}$ & $H_{10}$ & $H_{11}$ & $H_{12}$ & $H_{13}$ & $H_{14}$ & $H_{15}$ \\
\hline & & 2 & 3 & 4 & 5 & 6 & 7 & 9 & 10 & 11 & 12 & 13 & 14 & 15 \\
\hline 16 & 17 & 18 & 19 & 20 & 21 & 22 & 23 & 25 & 26 & & 28 & 29 & 30 & 31 \\
\hline \multirow{12}{*}{32} & 33 & 34 & 35 & 36 & 37 & 38 & 39 & 41 & 42 & 43 & 44 & 45 & 46 & 47 \\
\hline & 49 & 50 & 51 & 52 & 53 & 54 & 55 & 57 & & 59 & 60 & 61 & 62 & 63 \\
\hline & 65 & 66 & 67 & 68 & 69 & 70 & 71 & 73 & & 75 & 76 & 77 & 78 & 79 \\
\hline & 81 & 82 & 83 & 84 & 85 & 86 & 87 & & & 91 & 92 & 93 & 94 & 95 \\
\hline & & 98 & 99 & 100 & 101 & 102 & 103 & & & 107 & & 109 & 110 & 111 \\
\hline & & 114 & 115 & & & 118 & 119 & & & 123 & & & 126 & 127 \\
\hline & & 130 & 131 & & 133 & 134 & 135 & & & & & 141 & 142 & 143 \\
\hline & & 146 & 147 & & 149 & 150 & 151 & & & & & 157 & 158 & 159 \\
\hline & & & 163 & & 165 & & 167 & & & & & 173 & 174 & 175 \\
\hline & & & & & 181 & & 183 & & & & & & 190 & 191 \\
\hline & & & & & & & 199 & & & & & & 206 & 223,239 \\
\hline & & & & & & & 215,231 & & & & & & 222 & 255,271 \\
\hline
\end{tabular}

starting with $G_{5}$ and $G_{6}$ in Figure 4 , we obtain the graphs with RF-values $78,86,94,102, \ldots$ and $52,60,68,76, \ldots$, respectively.

Corollary 7. The reformulated F-index of a tree (or molecular) graph can be any positive even integer, except for 4, 6, $8,12,14,16,20,22,28,30,36,38,46,54$, and 62 .

\section{Conclusion}

The inverse problem is one of the recent problems of graph theory related to the applicative area. Here, we have studied the IP based on some topological graph indices such as $Y$-index, Gourava indices, second hyper-Zagreb index, reformulated first Zagreb index, and reformulated $F$-index. We have studied the inverse problems for the aforesaid indices since they are closely related to each other. We have also investigated the results for tree, molecular, unicyclic, and bicyclic graphs. The inverse problem is still open for other graph indices and other molecular structures.

\section{Data Availability}

No data were used to support this study.

\section{Conflicts of Interest}

The authors declare that there are no conflicts of interest regarding the publication of this article.

\section{References}

[1] H. Wiener, "Structural determination of paraffin boiling points," Journal of the American Chemical Society, vol. 69, no. 1, pp. 17-20, 1947.

[2] Y. C. Kwun, M. Munir, W. Nazeer, S. Rafique, and S. Min Kang, " $M$-Polynomials and topological indices of $V$-Phenylenic Nanotubes and Nanotori," Scientific Reports, vol. 7, no. 1, pp. 8756-8759, 2017.

[3] M. Munir, W. Nazeer, S. Rafique, and S. Kang, " $M$-polynomial and degree-based topological indices of polyhex nanotubes," Symmetry, vol. 8, no. 12, p. 149, 2016. 
[4] M. Munir, W. Nazeer, S. Rafique, and S. Kang, "M-polynomial and related topological indices of nanostar dendrimers," Symmetry, vol. 8, no. 9, p. 97, 2016.

[5] E. V. Gordeeva, M. S. Molchanova, and N. S. Zefirov, "General methodology and computer program for the exhaustive restoring of chemical structures by molecular connectivity indexes. Solution of the inverse problem in QSAR/QSPR," Tetrahedron Computer Methodology, vol. 3, no. 6, pp. 389-415, 1990.

[6] I. Gutman and N. Trinajstić, "Graph theory and molecular orbitals. Total $\varphi$-electron energy of alternant hydrocarbons," Chemical Physics Letters, vol. 17, no. 4, pp. 535-538, 1972.

[7] I. Gutman, B. Rucic, N. Trinajstic, and C. F. Wilcox, "Graph theory and molecular orbitals. XII. Acyclic polyenes," The Journal of Chemical Physics, vol. 62, no. 9, pp. 3399-3405, 1975.

[8] M. R. Farahani, M. R. Rajesh Kanna, and R. P. Kumar, "On the hyper-Zagreb indices of some nanostructures," Asian Academic Research Journal of Multidisciplinary, vol. 3, no. 1, pp. 115-123, 2016.

[9] V. R. Kulli, "The Gourava indices and coindices of graphs," Annals of Pure and Applied Mathematics, vol. 14, no. 1, pp. 33-38, 2017.

[10] A. Milicevic, S. Nikolic, and N. Trinajstic, "On reformulated Zagreb indices,” Molecular Diversity, vol. 8, pp. 393-399, 2004.

[11] J.-B. Liu, B. Ali, M. A. Malik, H. M. A. Siddiqui, and M. Imran, "Reformulated Zagreb indices of some derived graphs," Mathematics, vol. 7, no. 4, p. 366, 2019.

[12] A. Alameri, N. Al-Naggar, M. Al-Rumaima, and M. Alsharafi, " $Y$-index of some graph operations," International Journal of Applied Engineering Research, vol. 15, pp. 173-179, 2020.

[13] F. Asif, Z. Zahid, and S. Zafar, "Leap Zagreb and leap hyperZagreb indices of Jahangir and Jahangir derived graphs," Engineering and Applied Science Letters, vol. 3, no. 2, pp. 1-8, 2020.

[14] M. Numan, S. I. Butt, S. I. Butt, and A. Taimur, "Super cyclic antimagic covering for some families of graphs," Open Journal of Mathematical Sciences, vol. 5, no. 1, pp. 27-33, 2021.

[15] A. Tabassum, M. A. Umar, M. A. Umar, M. Perveen, and A. Raheem, "Antimagicness of subdivided fans," Open Journal of Mathematical Sciences, vol. 4, no. 1, pp. 18-22, 2020.

[16] A. B. Dainyak and A. D. Kurnosov, "On an extremal inverse problem in graph theory," Journal of Applied and Industrial Mathematics, vol. 9, no. 2, pp. 157-164, 2015.

[17] I. I. Baskin, E. V. Gordeeva, R. O. Devdariani, N. S. Zefirov, V. A. Palyulin, and M. I. Stankevich, "Methodology for solving the inverse problem of structure-property relationships for the case of topological indexes," Doklady Akademii Nauk SSSR, vol. 307, pp. 613-617, 1989.

[18] N. S. Zefirov, V. A. Palyulin, and E. V. Radchenko, "Problem of generation of structures with given properties solution of inverse problem for the case of centric Balaban index," Doklady Akademii Nauk SSSR, vol. 316, pp. 921924, 1991.

[19] I. Gutman and Y. Yeh, "The sum of all distances in bipartite graphs," Mathematica Slovaca, vol. 45, no. 4, pp. 327-334, 1995.

[20] S. G. Wagner, "A class of trees and its wiener index," Acta Applicandae Mathematica, vol. 91, no. 2, pp. 119-132, 2006.

[21] I. Gutman, M. Togan, A. Yurttas, A. S. Cevik, and I. N. Cangul, "Inverse problem for sigma index," MATCH Communications in Mathematical and in Computer Chemistry, vol. 79, pp. 491-508, 2018.
[22] X. Li, Y. Mao, and I. Gutman, "Inverse problem on the steiner wiener index," Discussiones Mathematicae Graph Theory, vol. 38, pp. 83-95, 2018.

[23] A. Yurtas, M. Togan, V. Lokesha, I. N. Cangul, and I. Gutman, "Inverse problem for Zagreb indices," Journal of Mathematical Chemistry, vol. 57, no. 2, pp. 609-615, 2019.

[24] M. Tavakoli and F. Rahbarnia, "Note on properties of first Zagreb index of graphs, Iran," Journal of Mathematical Chemistry, vol. 3, no. 1, pp. 1-5, 2012.

[25] X. Li, Z. Li, and L. Wang, "The inverse problems for some topological indices in combinatorial chemistry," Journal of Computational Biology, vol. 10, no. 1, pp. 47-55, 2003.

[26] É. Czabarka, L. Székely, and S. Wagner, “The inverse problem for Certain tree parameters," Discrete Applied Mathematics, vol. 157, no. 15, pp. 3314-3319, 2009.

[27] D. Maji and G. Ghorai, "A novel graph invariant: the third leap Zagreb index under several graph operations," Discrete Mathematics, Algorithms and Applications, vol. 11, no. 5, pp. 1-16, 2019.

[28] D. Maji and G. Ghorai, "Computing F-index, coindex and Zagreb polynomials of the $k$ th generalized transformation graphs," Heliyon, vol. 6, no. 12, Article ID e05781, 2020.

[29] D. Maji and G. Ghorai, "The first entire Zagreb index of various corona products and their bounds," Journal of Mathematical and Computational Science, vol. 11, no. 5, pp. 6018-6044, 2021.

[30] M. I. Skvortsova, I. I. Baskin, I. I. Baskin, O. L. Slovokhotova, V. A. Palyulin, and N. S. Zefirov, "Inverse problem in QSAR/ QSPR studies for the case of topological indexes characterizing molecular shape (Kier indices)," Journal of Chemical Information and Computer Sciences, vol. 33, no. 4, pp. 630634, 1993.

[31] M. Togan, A. Yurttas, U. Sanli, F. Celik, and I. Cangual, "Inverse problem for Bell index," Filomat, vol. 34, no. 2, pp. 615-621, 2020.

[32] M. Togan, A. Yurttas, and I. N. Cangul, "Inverse problem for the first entire Zagreb index," Advanced Studies in Contemporary Mathematics, vol. 29, pp. 161-169, 2019.

[33] D. Goldman, S. Istrail, G. Lancia, A. Piccolboni, and B. Walenz, "Algorithmic strategies in combinatorial chemistry," in Proceedings of the 11th ACM-SIAM Syposium on Discrete Algorithms, pp. 275-284, Philadelphia, PA, USA, 2000.

[34] Z. Du and A. Ali, "The inverse Wiener polarity index problem for chemical trees," PLoS One, vol. 13, Article ID e0197142, 2018.

[35] J. V. Kureethara, A. Asok, and I. N. Cangul, "Inverse problem for the forgotten and the hyper Zagreb indices of trees," Communications in Combinatorics and Optimization, pp. 1-7, 2021. 